\title{
Genetics and Breeding of Heat Tolerance in Rice
}

\author{
Changrong Ye, Xiaolin Li, Edilberto Redoña, Tsutomu Ishimaru, \\ and Krishna Jagadish
}

\begin{abstract}
Extreme weather events, especially heat waves, have become more frequent with global warming. High temperature significantly affects world food security by decreasing crop yield. Rice is intensively planted in tropical and subtropical areas in Asia, where high temperature has become a major factor affecting rice production. Rice is sensitive to high temperature, especially at booting and flowering stages. Rice varieties tolerant of high temperature are rare, and only a few heattolerant rice varieties have been identified. High temperature at booting and flowering stages causes sterile pollen, decreased pollen shedding, and poor pollen germination, which finally lead to a yield decrease. Heat-tolerant QTLs have been identified in different studies, but new breeding lines with considerable heat tolerance have not been bred using identified heat-tolerance donors and QTLs. Research on heat-tolerant donor identification, QTL mapping, gene cloning, and large-scale phenotyping technology is important for developing heat-tolerant rice varieties.
\end{abstract}

Keywords Rice $\cdot$ Heat tolerance $\cdot$ Global warming $\cdot$ High temperature

\author{
C. Ye $(\bowtie)$ \\ Center for Molecular Breeding Technology Invention and Development, Huazhi \\ Biotechnology Co. Ltd., Changsha, Hunan, China \\ e-mail: changrong.ye@higentec.com \\ X. Li \\ Institute of Food Crops, Yunnan Academy of Agricultural Sciences, Kunming, Yunnan, China \\ E. Redoña \\ Delta Research and Extension Center, Mississippi State University, Stoneville, MS, USA \\ e-mail: edredona@drec.msstate.edu \\ T. Ishimaru \\ Hokuriku Research Station, Central Region Agricultural Research Center, National \\ Agriculture and Food Research Organization, Niigata, Japan \\ e-mail: cropman@affrc.go.jp \\ K. Jagadish \\ Department of Agronomy, Kansas State University, Manhattan, KS, USA \\ e-mail: kjagadish@ksu.edu
}


Global temperature has been increasing rapidly since the last century, and high temperature has become a major factor affecting agricultural production. Rice is one of the crops most affected by high temperature. Heat tolerance of rice has been studied since the 1970s, but the progress attained has been quite slow. Evaluation of rice heat tolerance at different growth stages revealed that flowering stage is the most sensitive stage, and booting stage is the second most sensitive stage (Yang and Heilman 1993; Yoshida et al. 1981). Thus, recent findings and future prospects on heat tolerance of rice at these reproductive stages are the main focus in this review.

\section{Climate Change and Global Warming}

Climate change is the long-term change in weather patterns. Climate change is caused by factors such as biotic processes, variations in solar radiation received by Earth, plate tectonics, and volcanic eruptions. Certain human activities have been identified as primary causes of ongoing climate change, often referred to as global warming (Pachauri and Reisinger 2007).

Global warming is the long-term rise in the average temperature of Earth's climate system. Climate proxies show that the temperature had been relatively stable over 1000 or 2000 years before 1850. From 1880 to 2012, the global average (land and ocean) surface temperature increased by $0.85(0.65-1.06){ }^{\circ} \mathrm{C}$. From 1906 to 2005 , Earth's average surface temperature rose by $0.74 \pm 0.18{ }^{\circ} \mathrm{C}$ (Solomon et al. 2007). Since the early twentieth century, Earth's mean surface temperature has increased by $0.8{ }^{\circ} \mathrm{C}$, with $0.6{ }^{\circ} \mathrm{C}$ of this hike occurring since 1980 (Jansen et al. 2007). Human influence has been the dominant cause of the observed warming since the mid-twentieth century (IPCC 2013). The largest human influence has been the emission of greenhouse gases (GHG) such as carbon dioxide, methane, and nitrous oxide. The greenhouse effect is the process by which absorption and emission of infrared radiation by gases in a planet's atmosphere warm its lower atmosphere and surface. Global mean surface temperatures for 2081-2100, relative to 1986-2005, are likely to increase by $0.3-1.7^{\circ} \mathrm{C}$ for the lowest and by $2.6-4.8^{\circ} \mathrm{C}$ for the highest GHG emission scenarios (IPCC 2013).

Global warming caused by human activities has become a major constraint for agricultural development and crop production. Studies have shown that the annual mean maximum and minimum temperatures increased by 0.35 and $1.13{ }^{\circ} \mathrm{C}$ for the period 1979-2003 at the International Rice Research Institute, Los Baños, Philippines (Peng et al. 2004). By 2080, most cropping areas in the world are likely to be exposed to record average air temperature (Battisti and Naylor 2009). Relatively small changes in mean temperature can result in disproportionately large changes in the frequency of extreme events (Rosenzweig et al. 2001). These extreme temperature events are likely to become more frequent with global warming (Tabaldi et al. 2006). Of the 13 warmest years since 1880, 11 occurred from 2001 to 2011 (i.e., every year starting with 2001), while 2011 was the warmest La Niña year in the period from 1950 to 2011 (NOAA 2011). 
Future climate change and associated impacts will differ from region to region. Anticipated effects include increasing global temperature, rising sea level, changing precipitation, and expansion of deserts in the subtropics (IPCC 2014). Other likely changes involve more frequent extreme weather events such as heat waves, droughts, heavy rainfall with floods, heavy snowfall, ocean acidification, and species extinctions due to shifting temperature regimes. Effects significant to human beings are the threat to food security from decreasing crop yields (Battisti and Naylor 2009).

\section{Rice Production and Heat Damage}

Rice is the most widely produced and consumed staple food for a large part of the world's human population, providing more than $20 \%$ of the calories. Rice is widely planted around the world, with about $90 \%$ of the total production from Asia (southern Asia 31.44\%, East Asia 30.68\%, Southeast Asia 27.75\%, and West and Central Asia $0.27 \%$ ), $4.86 \%$ from the Americas, $4.39 \%$ from Africa, $0.57 \%$ from Europe, and $0.04 \%$ from Oceania (data for 2016 from FAO statistics).

The world's top rice producers are mainly in Asia. Many of these Asian countries are located in the tropics and subtropics, where the temperature is high during the rice crop season, including part of China, India, Indonesia, Bangladesh, Vietnam, Myanmar, Thailand, the Philippines, Cambodia, Lao PDR, and Sri Lanka.

Temperature stress is a complex interaction of temperature intensity, duration, rapidity, and plant growth stage. Damage from extreme high temperature is particularly severe when it occurs at critical crop developmental stages, particularly the reproductive period. Optimum temperature is $20-30{ }^{\circ} \mathrm{C}$ during the reproductive stage, but temperatures surpassing $35{ }^{\circ} \mathrm{C}$ have critical negative effects on rice growth. High daytime temperatures in some of the major tropical rice-growing regions are already close to the threshold beyond which yield begins to decline (Prasad et al. 2006; Wassmann et al. 2009a).

Rice has been cultivated in a wide range of climatic environments. High temperature has more effects in the tropics and low-altitude valleys in some of the temperate regions. Above $32{ }^{\circ} \mathrm{C}$, spikelet sterility becomes a major factor affecting rice yield, even if sufficient growth occurs in other yield components (Matthews et al. 1995). Traditionally, farmers grow rice at optimal seasonal temperatures to maximize grain yield. However, with the increase in the frequency of extreme temperature events, climate change may increase the probability of overlapping peaks of temperature and the flowering period, which diminishes final yield (Teixeira et al. 2011).

Although there has been no systematic monitoring and evaluation of temperature stress-induced yield losses worldwide, heat-vulnerable regions were geographically mapped based on the critical temperatures at flowering stage (Jagadish et al. 2014; Laborte et al. 2012; Wassmann et al. 2009a). Regional high-temperature damage was observed in many tropical and subtropical countries, such as Pakistan, India, Bangladesh, China, Thailand, Laos, Japan, Sudan, Australia, and the United States 
(Hasegawa et al. 2009; Ishimaru et al. 2016; Matsushima et al. 1982; Osada et al. 1973; Tian et al. 2009). Analysis of temperature and rice yield during 1992-2003 at the International Rice Research Institute (IRRI) showed that rice grain yield declined by $10 \%$ for each $1{ }^{\circ} \mathrm{C}$ increase in growing-season minimum temperature (Peng et al. 2004). Tian et al. (2009) reported that at least six severe heat events damaged the rice crop in the past 50 years in China. Studies on the Yangtze River basin in China showed that an estimated 3 million ha of rice were damaged and 5.18 million tons of paddy rice were lost in 2003 because of a heat wave with the temperature above $38^{\circ} \mathrm{C}$ lasting for more than 20 days (Li et al. 2004; Xia and Qi 2004; Yang et al. 2004). In Laos and southern India, the combined stress of heat and intense solar radiation during daytime increases the spikelet sterility of local popular cultivars when heading coincides with high temperatures (Ishimaru et al. 2016). In the record hot summer of 2007 , the percentage of spikelet sterility rose to $25 \%$ when the maximum daily temperature was around $38{ }^{\circ} \mathrm{C}$ in the temperate regions of Japan (Hasegawa et al. 2011). High temperature after heading significantly decreased rice grain quality in many rice-growing regions of Japan in 2010 (Morita et al. 2016). Thus, heat stress at flowering is a real threat to sustained rice production not only in tropical and subtropical regions but also in temperate regions.

The effect of extreme temperature events on crop production is likely to become more frequent in the near future. Significant yield losses have also been predicted by using different crop models. Short-term predictions indicated that, by 2030, rice production in South Asia could decrease by up to $10 \%$ (Lobell et al. 2008). Mediumto long-term predictions, that is, by 2080, estimated rice yields in developing countries to decrease by 10-25\%, while yields in India could drop by 30-40\% (Cline 2008). By 2100, rice and maize yields in the tropics are expected to decrease by $20-40 \%$ because of higher temperatures, without accounting for the decrease in yields as a result of drought enhanced by temperature increases (Battisti and Naylor 2009). Spatial model simulation indicated that yield of boro rice in Bangladesh could decrease by $20 \%$ and $50 \%$ by 2050 and 2070, respectively (Basak et al. 2010), and, on average, rice yields could decline by up to $33 \%$ by $2081-2100$ (Karim et al. 2012).

Besides high day temperatures, night temperatures greater than $29{ }^{\circ} \mathrm{C}$ can decrease spikelet fertility in rice with a subsequent decrease in seed set and grain yield (Satake and Yoshida 1978; Ziska et al. 1996). The increase in night temperature from 27 to $32{ }^{\circ} \mathrm{C}$ decreased grain length and grain width, thereby decreasing grain yield (Counce et al. 2005; Mohammed and Tarpley 2011; Morita et al. 2005).

\section{Heat Tolerance of Rice}

Heat tolerance is defined as the ability of the plant to grow and produce economic yield at high temperature (Wahid et al. 2007). The developmental stage at which the plant is exposed to heat stress determines the severity of the possible damage to the crop (Wahid et al. 2007). High temperature causes injury to the rice plant at 
different growth stages, such as poor germination, retarded seedling growth, leaf yellowing, inhibited rooting and tillering, inhibited panicle initiation and development, spikelet degeneration, disturbed pollen formation, poor panicle exsertion, inhibited anther dehiscence and pollination, and poor grain filling and development (Yang and Heilman 1993; Yoshida et al. 1981). Thus, heat tolerance is actually the responses of different traits to high temperature at different growth stages, for example, seedling growth or survival at the seedling stage, spikelet fertility at the reproductive stage, and chalkiness of grains at the grain-filling stage (Ishimaru et al. 2009; Lanning et al. 2011). At the grain-filling stage, high temperature affects cellular and developmental processes, leading to decreased fertility and grain quality (Barnabas et al. 2008). Decreased grain weight, decreased grain filling, and higher percentage of chalky grains are common effects of exposure to high temperature during the ripening stage in rice (Osada et al. 1973; Yoshida et al. 1981). In addition, increased temperature causes a serious decrease in grain size and amylase content (Yamakawa et al. 2007; Zhu et al. 2005).

Rice is relatively tolerant of high temperatures during the vegetative phase (Prasad et al. 2006; Yoshida et al. 1981), but is highly susceptible during the reproductive phase, particularly at flowering stage (Jagadish et al. 2008; Matsui et al. 2001b). High temperature surpassing $35^{\circ} \mathrm{C}$ during flowering stage increases pollen and spikelet sterility, which leads to significant yield losses, low grain quality, and low harvest index (Matsui et al. 1997a, b; Matsushima et al. 1982; Osada et al. 1973; Prasad et al. 2006; Zhong et al. 2005). The response of spikelet fertility is a major factor determining rice production under high-temperature conditions. Thus, spikelet fertility at high temperature has been widely used as a screening index for heat tolerance at the reproductive stage (Prasad et al. 2006).

Wide genetic variation exists in tolerance of heat stress (Matsui and Omasa 2002). Large cultivar variation exists in spikelet sensitivity to high-temperature damage, and the primary cause of this cultivar variation in heat tolerance at flowering is the number of viable pollen grains shed on the stigma, which is positively correlated with basal anther dehiscence (Matsui 2009).

It has been suggested that indica varieties are more tolerant of higher temperatures than japonica cultivars (Matsui et al. 2000; Satake and Yoshida 1978), although heat-tolerant genotypes have been found in both subspecies (Matsui et al. 2001b; Prasad et al. 2006).

Humidity also plays an important role in rice yield, as higher relative humidity $(\mathrm{RH})$ at the flowering stage at increased temperature affects spikelet fertility negatively (Yan et al. 2010). Field observations in some high-yielding rice areas with a drier climate and high temperatures (e.g., New South Wales and southern Iran) suggested no significant increase in spikelet sterility even at temperatures above $40{ }^{\circ} \mathrm{C}$ (Wassmann et al. 2009b). The fertility of spikelets at high air temperatures decreased further with increased humidity (Matsui et al. 1997a; Nishiyama and Satake 1981). An RH of $85-90 \%$ at the heading stage induced almost complete grain sterility in rice at a day/night temperature of $35 / 30^{\circ} \mathrm{C}$ (Abeysiriwardena et al. 2002). Increasing both air temperature and RH significantly increased spikelet sterility, while high temperature-induced sterility decreased significantly with decreasing RH. A 
reduction in sterility with decreased $\mathrm{RH}$ was more due to decreased spikelet temperature than to air temperature. Thus, both air temperature and humidity are equally important in determining pollen viability, splitting of anthers, pollen shedding, and spikelet sterility in rice. The impact of $\mathrm{RH}$ should be considered when interpreting the effect of high temperature on grain sterility.

Heat tolerance at flowering is often tested at $37.5-38.0{ }^{\circ} \mathrm{C}$ (with relative humidity of 60-70\%) to have a great contrast in spikelet fertility between susceptible and tolerant genotypes (Mackill et al. 1982; Satake and Yoshida 1978; Ye et al. 2015b, 2012). At the booting stage, $38{ }^{\circ} \mathrm{C}$ is a threshold for most rice varieties. Similarly, we confirmed that $37^{\circ} \mathrm{C}$ is a threshold at flowering stage for most varieties. Above this limit, pollen development will fail and spikelet fertility will decline significantly (Ye et al. 2015b).

\section{Heat-Tolerant Rice Genetic Resources}

The response of rice to high temperatures differs according to the developmental stage. High-temperature tolerance at one developmental stage may or may not necessarily lead to tolerance during other stages (Wassmann et al. 2009a). Hence, the effect of high temperature during different developmental stages has to be partitioned and evaluated separately for assessing, identifying, and characterizing for genetic manipulation of tolerance mechanisms (Wahid et al. 2007). Since flowering stage is the most sensitive stage to high temperature, most screenings for heattolerant germplasm were done at flowering stage.

Rice genetic resources tolerant of high temperature have been identified in both indica (Matsui et al. 1997b) and japonica subspecies (Matsui et al. 2001b). N22 and Dular are excellent sources of genes for heat tolerance (Manigbas et al. 2014). Among the heat-tolerant varieties, N22, an Indian aus-type landrace, was identified as one of the most heat-tolerant genotypes in both chamber and open-field experiments (Jagadish et al. 2010a; Mackill et al. 1982; Manigbas et al. 2014; Poli et al. 2013; Prasad et al. 2006; Ye et al. 2012; Yoshida et al. 1981). N22 has been used as a check variety for many studies on heat tolerance. Akitakomachi is the most tolerant genotype found among japonica rice (Matsui et al. 2001b).

A recent investigation using a representative set of popular cultivars grown across highly vulnerable rice-growing regions of South and Southeast Asia, Latin America, and West Africa concluded that most of the popular rice cultivars were susceptible to heat stress at reproductive stages (Shi et al. 2015). More than $80 \%$ of hybrid rice combinations in China are heat-susceptible, but some heat-tolerant combinations were found in hybrid rice (Hu et al. 2012; Zhou et al. 2009). The hybrid rice Guodao 6 was considered as a heat-tolerant variety (Tao et al. 2008). An accession of wild rice, Oryza meridionalis $\mathrm{Ng}$, was also identified as a heat-tolerant species (Scafaro et al. 2010).

In japonica cultivars, Akitakomachi, Nipponbare, Hitomebore, and Todorokiwase (Maruyama et al. 2013; Matsui et al. 2001b; Tenorio et al. 2013) are classified as 
heat-tolerant genotypes. In indica cultivars, IR24, IR36, Ciherang, ADT36, BG90-2, Dular, Huanghuazhan, AUS17, M9962, Sonalee, and AUS16 (Cao et al. 2008; Cheabu et al. 2018; Maruyama et al. 2013; Shi et al. 2015; Tenorio et al. 2013) are known as heat-tolerant genotypes. It is notable that Giza178, an Egyptian cultivar developed from a japonica-indica cross, has considerable heat tolerance at booting stage as well as flowering stage (Tenorio et al. 2013).

Varieties such as Agbede, Carreon, Dular, N22, OS4, P1215936, and Sintiane Diofor have high spikelet fertility even at high temperatures (Yoshida et al. 1981). The local Iranian landraces Anbori and Hoveaze (probably the same as Hoveyzeh) are tolerant of high temperatures (Gilani et al. 2009). Cultivars KRN, Citanduy, Belle patna, and BPB were tolerant of high-temperature treatment at the ripening stage (Zakaria et al. 2002). An indica cultivar (HT54) from China was tolerant of high temperature at both seedling and grain-filling stages. HT54 seedlings could tolerate high temperature up to $48^{\circ} \mathrm{C}$ for $79 \mathrm{~h}$ (Wei et al. 2013). New Rice for Africa line 44 (NERICA-L-44) was also identified as heat tolerant at both vegetative and reproductive stages (Bahuguna et al. 2015).

As part of IRRI's initiative to develop improved breeding lines tolerant of high temperature, studies were conducted to identify genetic donors of the heat-tolerance trait from the IRRI Genebank. A series of trials were conducted using a set of 455 IRRI Genebank accessions coming from "hot" countries (Pakistan, India, Afghanistan, Iran, and Iraq). However, few varieties (about 5\%) showed some degree of heat tolerance. Twenty-three accessions were selected as potential donors for heat tolerance. Dular and Todorokiwase are tolerant at the booting stage, while Milyang23 and IR2006-P12-12-2-2 are tolerant at the flowering stage. Giza178 is tolerant at both booting and flowering stages. Darbari Roodbar, Larome, Mulai, Giza178, IR2006-P-12-12-2-2, Milyang23, and Todorokiwase were tolerant of high temperature in the field and growth chambers. Other potential donors identified based on at least one trait were IR22, IR2307-247-2-2-3, IR6, IR8, MRC603-383, Ganjay, Todorokiwase, Giza 178, Giza 159, and Toor Thulla (Tenorio et al. 2013). The accessions with heat tolerance at booting and flowering stage are useful genotypes for a breeding program to improve heat resilience in terms of spikelet sterility.

\section{Physiology of Heat Tolerance in Rice}

Flowering stage is the most susceptible to high temperatures, followed by booting stage. High temperature is more injurious if it occurs just before or during anthesis (Satake and Yoshida 1978). Exposure to $41^{\circ} \mathrm{C}$ for $4 \mathrm{~h}$ at flowering caused irreversible damage and plants became completely sterile, whereas this high temperature $\left(41{ }^{\circ} \mathrm{C}\right.$ ) had no effect on spikelet fertility at 1 day before or after flowering (Yoshida et al. 1981). The same study also found that pollination of heat-stressed stigmas with unstressed pollen as well as self-pollination at $1 \mathrm{~h}$ before heat stress application did not affect spikelet fertility. These analyses indicated that the heat-sensitive stage is about $1 \mathrm{~h}$ before and after flowering. High temperature affects anther dehiscence, 
pollination, and pollen germination, which then leads to spikelet sterility and yield loss (Yoshida et al. 1981). Exposure at anthesis even for just 1-2 $\mathrm{h}$ of high temperature may result in high spikelet sterility (Jagadish et al. 2007).

High temperature at booting stage mainly decreases the fertility of pollen grains, while at flowering stage, it mainly decreases the number of pollens shedding on the stigma and the germination of pollen grains. The decreased production of pollens at elevated temperatures may be attributable to impaired cell division of the microspore mother cells (Takeoka et al. 1992). The major causes of high temperatureinduced sterility were decreased pollen shedding and decreased viability of pollen grains, resulting in a lower number of germinated pollen grains on the stigma (Mackill et al. 1982; Satake and Yoshida 1978).

Among physiological processes occurring at anthesis, anther dehiscence is perceived to be the most critical stage affected by high temperature (Matsui et al. 1997a, b, 2000, 2001a). Spikelet opening triggers rapid pollen swelling, leading to anther dehiscence and pollen shedding from the anthers' apical and basal pores (Matsui et al. 2000). Increased basal pore length in a dehisced anther was found to contribute significantly to successful pollination (Matsui and Omasa 2002). The anthers of heat-tolerant cultivars dehisce more easily than those of susceptible cultivars under high-temperature conditions (Mackill et al. 1982; Matsui et al. 1997a, b, 2001b; Satake and Yoshida 1978). This is because of the tight closure of the locule by the cell layers, which delays locule opening and decreases spikelet fertility at high temperature (Matsui and Omasa 2002).

In heat-tolerant cultivar N22, the dehiscence of anthers begins soon after the glumes open and is completed when the anthers are still situated inside the glumes on short filaments; thus, pollen grains of N22 could be easily shed onto stigma at that time (Satake and Yoshida 1978). The heat-tolerant cultivar Nipponbare had well-developed cavities in anthers and thick locule walls, which enabled easy rupture of the septa in response to swelling of pollen (Matsui et al. 2001b).

Rice plants, when exposed to high temperatures during critical stages, can avoid heat by maintaining their microclimate temperature below critical levels by efficient transpiration cooling (Wassmann et al. 2009a). Lower relative humidity of 60\% at $38^{\circ} \mathrm{C}$ leads to a higher vapor pressure deficit, facilitating the plant in exploiting its transpiration cooling ability (Jagadish et al. 2007). On the basis of the interaction between high temperature and relative humidity, rice cultivation regions in the tropics and subtropics can be classified into hot/dry and hot/humid regions. It can be assumed that rice cultivation in hot/dry regions where temperatures may exceed $40{ }^{\circ} \mathrm{C}$ (e.g., Pakistan, Iran, and India) has been facilitated through unintentional selection for efficient transpiration cooling under sufficient supply of water. An exceptionally high temperature difference of $6.8^{\circ} \mathrm{C}$ between crop canopy and ambient air temperature $\left(34.5^{\circ} \mathrm{C}\right)$ was recorded in the Riverina region of New South Wales, Australia (Matsui et al. 2007). Rice pollen is extremely sensitive to temperature and relative humidity and loses its viability within 10 min of shedding (Matsui et al. 1997a). Tolerant cultivar Shanyou63 showed a significantly slower decrease in pollen activity, pollen germination, and rate of floret fertility vis-à-vis susceptible cultivar Teyou559 at $39{ }^{\circ} \mathrm{C}$ (Tang et al. 2008). 
The temperature inside the spikelet decreases with a reduction in relative humidity, possibly because of the enhancement of transpiration at low relative humidity (Weerakoon et al. 2008). This decrease in temperature inside the spikelet increases the viability of pollen grains. Viable pollen grains absorb moisture and swell at moderate to high relative humidity and create the required pressure for the rupture of the septum, which helps in the deposition of pollen on stigma and thus produces a fertilized spikelet (Weerakoon et al. 2008). The panicle temperature of Chinese hybrid rice exceeded the ambient air temperature by $4{ }^{\circ} \mathrm{C}$ under humid and low wind conditions and also caused a severe decrease in spikelet fertility (Tian et al. 2010).

Cultivar NL-44 has high heat tolerance at both vegetative and reproductive stages. NL-44 under extreme heat stress retained the ability to maintain higher chlorophyll (relative greenness) and photosynthesis, a feature that could sustain its survival under severe heat stress during both the vegetative and reproductive stages. NL-44 and the heat-tolerant check N22 consistently displayed lower membrane damage and higher antioxidant enzyme activity across leaves and spikelets (Bahuguna et al. 2015).

\section{Genetics of Heat Tolerance in Rice}

Heat tolerance is controlled by not only one major gene but also several genes. The identification of quantitative trait loci (QTLs) is a promising approach to dissect the genetic basis of heat tolerance. By using genetic resources with heat tolerance at flowering, QTL mapping studies for heat tolerance (spikelet fertility) have been conducted on various rice populations at booting (Zhao et al. 2006) and flowering stages (Cao et al. 2003; Chen et al. 2008; Cheng et al. 2012; Jagadish et al. 2010a; Xiao et al. 2011b; Ye et al. 2015b, 2012; Zhang et al. 2009, 2008). About 60 QTLs associated with heat tolerance at flowering stage have been identified so far. For example, two major QTLs were identified on chromosome 1 (qHTSF 1.1) and chromosome 4 (qHTSF4.1) in an IR64/N22 population. These two major QTLs could explain 12.6\% (qHTSF1.1) and $17.6 \%$ ( $q$ HTSF4.1) of the variation in spikelet fertility at high temperature (Ye et al. 2012). Four QTLs were identified in an IR64/Giza178 population, two other QTLs were identified in a Milyang23/Giza178 population, and five QTLs were identified in the three-way cross population IR64//Milyang23/Giza178. Three of these QTLs were identified in both biparental and three-way populations (Ye et al. 2015b). Recently, two QTLs with high genetic effect (qSTIPSS9.1 and $q S T I Y 5.1 / q S S I Y 5.2)$ were mapped in less than $400 \mathrm{kbp}$ genomic regions (Shanmugavadivel et al. 2017). QTLs for other heat tolerance-related traits such as anther length, apical dehiscence length, basal dehiscence length, and percentage of longitudinal dehiscence (Tanveer et al. 2015) and pollen fertility (Xiao et al. 2011a) were also detected. 
Among the several identified QTLs, the most promising QTLs for heat tolerance across different genetic backgrounds and locations have been identified on chromosomes 1 and 4 (Jagadish et al. 2010a; Xiao et al. 2011b; Ye et al. 2015b, 2012). The heat-tolerant QTL (qHTSF4.1) on chromosome 4 was identified in different populations of heat-tolerant rice varieties 996, N22, Milyang23, and Giza178 (Raddatz et al. 2001; Xiao et al. 2011b; Ye et al. 2012). The QTL interval was fine-mapped to $1.2 \mathrm{Mb}$. The heat tolerance (spikelet fertility) of the near-isogenic line (NIL) carrying qHTSF4.1 increased consistently in all of the backcross populations. In $\mathrm{BC}_{3} \mathrm{~F}_{3}$, the spikelet fertility of plants with qHTSF4.1 $(34.7 \pm 14.2 \%)$ was significantly higher than in those without the QTL $(22.5 \pm 7.9 \%)$ and in the recurrent parent IR64 (15.1 $\pm 6.3 \%)$, whereas, in $\mathrm{BC}_{5} \mathrm{~F}_{2}$, the spikelet fertility of plants with qHTSF4.1 $(44.6 \pm 13.1 \%)$ was significantly higher than in plants without the QTL $(27.1 \pm 9.6 \%)$ and in the recurrent parent IR64 (19.4 $\pm 8.4 \%)$ (Ye et al. 2015a).

Recently, a thermotolerance gene $(T T 1)$ in African rice $(O$. glaberrima) variety CG14 was identified and cloned ( $\mathrm{Li}$ et al. 2015). Gene TT1 encodes an $\alpha 2$ subunit of the $26 \mathrm{~S}$ proteasome involved in the degradation of ubiquitinated proteins. Ubiquitylome analysis indicated that $O g T T 1$ protects cells from heat stress through more efficient elimination of cytotoxic denatured proteins and more effective maintenance of heat-response processes than achieved with OsTT1. Overexpression of $O g T T 1$ was associated with markedly enhanced thermotolerance in rice at seedling, flowering, and grain-filling stages ( $\mathrm{Li}$ et al. 2015). A gene for heat tolerance at seedling stage (OsHTAS) was also cloned and characterized. OsHTAS encodes a ubiquitin ligase localized in the nucleus and cytoplasm. OsHTAS was responsive to multiple stresses and was strongly induced by exogenous ABA. OsHTAS modulated hydrogen peroxide accumulation in shoots, altered the stomatal aperture status of rice leaves, and promoted ABA biosynthesis. The RING finger ubiquitin E3 ligase OsHTAS functions in leaf blades to enhance heat tolerance through modulation of hydrogen peroxide-induced stomatal closure and is involved in both ABA-dependent and drought- and salt-tolerance-mediated pathways (Liu et al. 2016).

Reverse genetic approaches were also employed to identify the genes for heat tolerance at anthesis. Expression analyses revealed that at least 13 genes were designated as high temperature-repressed genes in the anther. These genes were expressed specifically in the immature anther, mainly in the tapetum at the microspore stage, and downregulated after 1 day of high temperature. High temperatures may disrupt some of the tapetum functions required for pollen adhesion and germination on the stigma (Endo et al. 2009).

A proteomic analysis compared proteins expressed in heat-stressed anthers from three rice varieties with different temperature tolerances. The temperature-tolerant rice genotype (N22) showed a higher accumulation of small heat shock proteins (sHSP) than the temperature-sensitive rice genotype (Moroberekan). The moderately tolerant rice genotype (IR64) showed intermediate sHSP accumulation. The accumulation of sHSP may confer greater heat tolerance in N22 rice (Jagadish et al. 2010b). 


\section{Breeding of Heat Tolerance in Rice}

Breeding heat-tolerant rice is one of the most important strategies used to mitigate the effects of climate change, particularly in the hot Asian countries where most rice is grown. However, breeding rice varieties tolerant of high temperature has so far received little attention as compared to other abiotic stresses such as drought and salinity. After one comprehensive study in the early 1980s (Mackill 1981; Mackill and Coffman 1983; Mackill et al. 1982), high-temperature tolerance of rice has been treated only within region-specific breeding programs, with limited success. Using identified genetic resources and QTLs to improve heat tolerance in rice varieties has not been achieved.

QTLs for rice heat tolerance at flowering have been mapped on all chromosomes by using various rice populations (Cao et al. 2003; Chen et al. 2008; Cheng et al. 2012; Jagadish et al. 2010a; Xiao et al. 2011b; Zhang et al. 2009, 2008). However, the additive effect of each QTL is low. Introducing one or a few QTLs into a variety may not sufficiently increase its heat tolerance. Therefore, it is necessary to validate and characterize more QTLs and design SNP chips with QTL-linked markers to accelerate selection and incorporation of multiple QTLs to improve the efficiency of heat-tolerance breeding.

To mitigate heat-induced spikelet sterility, two strategies have been proposed. One is to develop cultivars that shed larger numbers of pollen grains or produce pollen grains able to germinate at high temperatures. Another strategy is to breed cultivars that escape heat at flowering because of their early-morning flowering (EMF) trait (Satake and Yoshida 1978). The EMF trait could be beneficial for decreasing yield loss from rising temperatures. The use of germplasm with the EMF trait could help to diminish anticipated yield losses caused by spikelet sterility at anthesis as a result of expected global warming (Ishimaru et al. 2010).

Spikelets are highly susceptible to heat stress at flowering; however, they remain fertile when flowering occurs $1 \mathrm{~h}$ prior to heat stress, because fertilization is completed within $1 \mathrm{~h}$ after flowering (Satake and Yoshida 1978). Shifting the time of anthesis to early hours of the cooler morning will help plants to escape hightemperature stress during processes of pollen shed, pollination, and fertilization and can thus minimize sterility caused by high temperatures. It has been suggested that there is a potential for genetic improvement to advance flowering to an earlier time of day in current high-yielding cultivars (Nishiyama and Blanco 1980). The EMF strategy has been used to produce introgression lines with the EMF trait transferred from wild rice $O$. officinalis. EMF NILs carrying $q E M F 3$ had earlier flower opening time by $1.5-2.0 \mathrm{~h}$ than recurrent parents, which decreased heat-induced sterility at flowering at elevated temperature. It was demonstrated that the shift in flower opening time to early morning is effective for escaping from heat stress at flower opening (Hirabayashi et al. 2015; Ishimaru et al. 2010). Pyramiding lines with QTLs for heat tolerance ( $q H T S F 4.1)$ and EMF ( $q E M F 3$ ) effectively improved heat tolerance at flowering in both controlled and field conditions. 
The development of new heat-tolerant rice varieties is among the best approaches to address changing climatic conditions in affected farming communities. Breeding heat-tolerant rice began in 2010 in the Philippines to develop new rice genotypes that could adapt to changing climatic and local farming conditions. By combining a heat-tolerant donor parent, such as N22, with high-yielding and better cultivars, selecting new genotypes with better adaptation to emerging climatic conditions is possible (Manigbas et al. 2014).

To increase the heat tolerance of a rice variety named Improved White Ponni (IWP), heat-tolerance QTLs qHTSF1.1 and qHTSF4.1 (Ye et al. 2012) were introgressed from Nagina 22 into IWP through marker-assisted breeding. The progenies harboring both qHTSF1.1 and qHTSF4.1 showed higher fertility percentages under high-temperature stress at the flowering stage. The results confirmed that these QTLs were responsible for maintaining membrane integrity and yield under elevated-temperature conditions (Vivitha et al. 2017).

Moreover, recent studies showed that heat tolerance at flowering stage in rice is controlled by recessive genes (Fu et al. 2015; Ye et al. 2015b, 2012). Thus, both parents should possess high-temperature tolerance to develop heat-tolerant $\mathrm{F}_{1}$ combinations. Male parents play a more important role in heat-tolerant combinations than female parents. The heat susceptibility of hybrid rice in China is mainly due to the wide application of heat-susceptible restorer lines with high yield in three-line hybrid rice breeding (Fu et al. 2015). Therefore, it is important to improve the heat tolerance of both parents of hybrid rice combinations.

\section{Future Prospects}

Booting and flowering are the stages most sensitive to high temperature, which may sometimes lead to significant sterility. Great variation exists among rice germplasm in response to temperature stress. Flowering at cooler times of day, more pollen viability, larger anthers, longer basal dehiscence, and the presence of long basal pores are some of the phenotypic markers for high-temperature tolerance. Replacement of heat-sensitive cultivars with heat-tolerant ones, adjustment of sowing time, choice of varieties with a growth duration allowing avoidance of peak stress periods, and exogenous application of plant hormones are some of the adaptive measures that will help to mitigate the forecast yield decrease due to global warming (Shah et al. 2011). Staggered planting dates and short-duration varieties are advocated as some of the options to escape from high-temperature stress. Synchronizing critical growth stages with most favorable weather is another practice for avoiding extreme temperature. However, cultural practices alone are not adequate and yield loss can be minimized further by combining such methods with genetic improvement.

There is a continuous need to integrate disciplines, such as structural genomics, transcriptomics, proteomics, and metabolomics, with plant physiology and plant breeding (Varshney et al. 2005). By using the wide diversity of rice germplasm, we 
will be able to explore the novel QTLs and alleles that are expected to have different effects from the identified QTLs. However, conventional breeding still offers an opportunity for significant and predictable incremental improvements in hightemperature tolerance of new rice cultivars. Among the QTLs identified for rice heat tolerance at flowering stage, even QTLs with a large effect can explain only approximately $20 \%$ of the variation, and the additive effect of each QTL is low. Introducing one or a few QTLs into a genetic background may not be sufficient to significantly increase its heat tolerance. More heat-tolerance donors and QTLs need to be identified and used in our breeding programs.

Heat-induced spikelet sterility at flowering and early-morning flowering is difficult traits for precise phenotyping in large mapping populations. Future research activities should be aimed at identifying and breeding heat-tolerant germplasm accessions that exploit the variation in both genotypic and morphological characters. Several approaches should be actively exploited to improve heat tolerance in current cultivars, including discovery and exploitation of new genes and alleles, improved breeding efficiency, marker-assisted selection, and genetic modification (Shah et al. 2011). Marker-assisted gene pyramiding and marker-assisted recurrent selection can be used to improve breeding efficiency for heat tolerance. The cloning of causal genes will unveil the complex genetic control of each trait under heat stress. Further genetic efforts are required for the development of heat-resilient rice varieties to cope with the challenges of climate change.

\section{References}

Abeysiriwardena DS, Ohba K, Maruyama A (2002) Influence of temperature and relative humidity on grain sterility in rice. J Natl Sci Found Sri Lanka 30:33-41

Bahuguna RN, Jha J, Madan P, Shah D, Lawas ML, Khetarpal S, Jagadish S (2015) Physiological and biochemical characterization of NERICA-L 44: a novel source of heat tolerance at the vegetative and reproductive stages in rice. Physiol Plant 154:543-559

Barnabas B, Jager K, Feher A (2008) The effect of drought and heat stress on reproductive processes in cereals. Plant Cell Environ 31:11-38

Basak J, Ali M, Islam MN, Rashid M (2010) Assessment of the effect of climate change on boro rice production in Bangladesh using DSSAT model. J Civ Eng 38:95-108

Battisti DS, Naylor R (2009) Historical warning of future food insecurity with unprecedented seasonal heat. Science 323:240-244

Cao L, Zhao J, Zhan X, Li D, He L, Cheng S (2003) Mapping QTLs for heat tolerance and correlation between heat tolerance and photosynthetic rate in rice. Chin J Rice Sci 17:223-227

Cao YY, Duan H, Yang LN, Wang ZQ, Zhou SC, Yang J (2008) Effect of heat stress during meiosis on grain yield of rice cultivars differing in heat tolerance and its physiological mechanism. Acta Agron Sin 34:2134-2142

Cheabu S, Moung-Ngam P, Arikit S, Vanavichit A, Malumpong C (2018) Effects of heat stress at vegetative and reproductive stages on spikelet fertility. Rice Sci 25:218-226

Chen Q, Yu S, Li C, Mou T (2008) Identification of QTLs for heat tolerance at flowering stage in rice. Sci Agric Sin 41:315-321

Cheng L, Wang J, Uzokwe V, Meng L, Wang Y, Sun Y, Zhu L, Xu J, Li Z (2012) Genetic analysis of cold tolerance at seedling stage and heat tolerance at anthesis in rice. J Integr Agric 11:359-367 
Cline W (2008) Global warming and agriculture. International Monetary Fund, Washington, DC. http://www.imf.org/external/pubs/ft/fandd/2008/03/pdf/cline.pdf. Accessed 5 Aug 2018

Counce PA, Bryant RJ, Bergman CJ, Bautista RC, Wang YJ, Siebenmorgen TJ, Modenhauer KAK, Meullenet J (2005) Rice milling quality, grain dimensions, and starch branching as affected by high night temperatures. Cereal Chem 82:645-648

Endo M, Tsuchiya T, Hamada K, Kawamura S, Yano K, Ohshima M, Higashitani A, Watanabe M, Kawagishi-Kobayashi M (2009) High temperatures cause male sterility in rice plants with transcriptional alterations during pollen development. Plant Cell Physiol 50:1911-1922

Fu G, Zhang C, Yang Y, Xiong J, Yang X, Zhang X, Jin Q, Tao L (2015) Male parent plays a more important role in heat tolerance in three-line hybrid rice. Rice Sci 22:116-122

Gilani AA, Siadat SA, Alami Saeed K, Bakhshandeh AM, Moradi F, Seidnejad M (2009) Effect of heat stress on grain yield stability, chlorophyll content and cell membrane stability of flag leaf in commercial rice cultivars in Khuzestan. Iranian J Crop Sci 11(1):82-100

Hasegawa T, Yoshimoto M, Kuwagata T, Ishigooka Y, Kondo M, Ishimaru T (2009) The impact of global warming on rice production: lessons from spikelet sterility observed under the record hot summer of 2007. NIAES annual report 2008. NIAES, Tsukuba, pp 23-25

Hasegawa T, Ishimaru T, Kondo M, Kuwagata T, Yoshimoto M, Fukuoka M (2011) Spikelet sterility of rice observed in the record hot summer of 2007 and the factors associated with its variation. J Agric Meteorol 67:225-232

Hirabayashi H, Sasaki K, Kambe T, Gannaban RB, Miras MA, Mendioro MS, Simon EV, Lumanglas PD, Fujita D, Takemoto-Kuno Y, Takeuchi Y, Kaji R, Kondo M, Kobayashi N, Ogawa T, Ando I, Jagadish KS, Ishimaru T (2015) qEMF3, a novel QTL for the early-morning flowering trait from wild rice, Oryza officinalis, to mitigate heat stress damage at flowering in rice, O. sativa. J Exp Bot 66:1227-1236

Hu SB, Zhang YP, Zhu DF, Lin XQ, Xiang J (2012) Evaluation of heat resistance in hybrid rice. Chin J Rice Sci 26:751-756

IPCC (2013) Climate change 2013: the physical science basis. Cambridge University Press, Cambridge; New York, NY

IPCC (2014) Climate change 2014: impacts, adaptation and vulnerability: Part A: Global and sectoral aspects: Working Group II contribution to the IPCC Fifth Assessment report. Cambridge University Press, Cambridge

Ishimaru T, Horigan AK, Ida M, Iwasawa N, San-Oh YA, Nakazono M, Nishizawa NK, Masumura T, Kondo M, Yoshida M (2009) Formation of grain chalkiness and changes in water distribution in developing rice caryopses grown under high-temperature stress. J Cereal Sci 50:166-174

Ishimaru T, Hirabayashi H, Ida M, Takai T, San-Oh YA, Yoshinaga S, Ando I, Ogawa T, Kondo M (2010) A genetic resource for early-morning flowering trait of wild rice Oryza officinalis to mitigate high temperature-induced spikelet sterility at anthesis. Ann Bot 106:515-520

Ishimaru T, Seefong X, Nallathambi J, Rajendran S, Yoshimoto M, Phoudalay L, Benjamin S, Hasegawa T, Hayashi K, Gurusamy A, Muthurajan R, Jagadish S (2016) Quantifying rice spikelet sterility in potential heat-vulnerable regions: field surveys in southern Laos and southern India. Field Crop Res 190:3-9

Jagadish SVK, Craufurd PQ, Wheeler T (2007) High temperature stress and spikelet fertility in rice. J Exp Bot 58:1627-1635

Jagadish SVK, Craufurd PQ, Wheeler T (2008) Phenotyping rice mapping population parents for heat tolerance during anthesis. Crop Sci 48:1140-1146

Jagadish SVK, Cairns J, Lafitte R, Wheeler TR, Price AH, Craufurd PQ (2010a) Genetic analysis of heat tolerance at anthesis in rice. Crop Sci 50:1633-1641

Jagadish SVK, Muthurajan R, Oane R, Wheeler TR, Heuer S, Bennett J, Craufurd PQ (2010b) Physiological and proteomic approaches to address heat tolerance during anthesis in rice. $\mathrm{J}$ Exp Bot 61:143-156

Jagadish SVK, Murty MVR, Quick W (2014) Rice responses to raising temperatures: challenges, perspectives and future directions. Plant Cell Environ 38:1686-1698 
Jansen E, Overpeck J, Briffa KR, Duplessy JC, Joos F, Masson-Delmotte V, Olago D, Otto-Bliesner B, Peltier WR, Rahmstorf S, Ramesh R, Raynaud D, Rind D, Solomina O, Villalba R, Zhang D (2007) Palaeoclimate. In: Solomon S, Qin D, Manning M, Chen Z, Marquis M, Averyt KB, Tignor M, Miller HL (eds) Climate change 2007: the physical science basis. Contribution of Working Group I to the Fourth Assessment report of the intergovernmental panel on climate change. Cambridge University Press, Cambridge; New York, NY

Karim MR, Ishikawa M, Ikeda M, Islam M (2012) Climate change model predicts 33\% rice yield decrease in 2100 in Bangladesh. Agron Sustain Dev 32:821-830

Laborte A, Nelson A, Jagadish K, Aunario J, Sparks A, Ye C, Redoña E (2012) Rice feels the heat. Rice Today 3:30-31

Lanning SB, Siebenmorgen TJ, Counce PA, Ambardekar AA, Mauromoustakos A (2011) Extreme night time air temperatures in 2010 impact rice chalkiness and milling quality. Field Crop Res 124:132-136

Li C, Peng C, Zhao Q, Xie P, Chen W (2004) Characteristic analysis of the abnormal high temperature in 2003 midsummer in Wuhan City. J Centr China Normal Univ 38:379-381

Li X, Chao D, Wu Y, Huang X, Chen K, Cui L, Su L, Ye W, Chen H, Chen H, Dong N, Guo T, Shi M, Feng Q, Zhang P, Han B, Shan J, Gao J, Lin H (2015) Natural alleles of a proteasome $\alpha 2$ subunit gene contribute to thermotolerance and adaptation of African rice. Nat Genet 47:827-833

Liu J, Zhang C, Wei C, Liu X, Wang M, Yu F, Xie Q, Tu J (2016) The RING finger ubiquitin E3 ligase OsHTAS enhances heat tolerance by promoting $\mathrm{H}_{2} \mathrm{O}_{2}$-induced stomatal closure in rice. Plant Physiol 170:429-443

Lobell DB, Burke MB, Tebaldi C, Mastrandrea MD, Falcon WP, Naylor RL (2008) Prioritizing climate change adaptation needs for food security in 2030. Science 319:607-610

Mackill DJ (1981) Studies on the mechanism and genetics of high temperature tolerance in rice. University of California-Davis, Davis, CA

Mackill DJ, Coffman W (1983) Inheritance of high temperature tolerance and pollen shedding in a rice cross. Z Pflanzen 91:61-69

Mackill DJ, Coffman WR, Rutger J (1982) Pollen shedding and combining ability for high temperature tolerance in rice. Crop Sci 22:730-733

Manigbas NL, Lambio LAF, Madrid LB, Cardenas C (2014) Germplasm innovation of heat tolerance in rice for irrigated lowland conditions in the Philippines. Rice Sci 21:162-169

Maruyama A, Weerakoon W, Wakiyama Y, Ohba K (2013) Effects of increasing temperatures on spikelet fertility in different rice cultivars based on temperature gradient chamber experiments. J Agron Crop Sci 199:416-423

Matsui T (2009) Floret sterility induced by high temperatures at the flowering stage in rice. Jpn J Crop Sci 78:303-311

Matsui T, Omasa K (2002) Rice cultivars tolerant to high temperature at flowering: anther characteristics. Ann Bot 89:683-687

Matsui T, Omasa K, Horie T (1997a) High temperature induced spikelet sterility of japonica rice at flowering in relation to air humidity and wind velocity conditions. Jpn J Crop Sci 66:449-455

Matsui T, Namuco OS, Ziska LH, Horie T (1997b) Effects of high temperature and $\mathrm{CO}_{2}$ concentration on spikelet sterility in indica rice. Field Crop Res 51:213-219

Matsui T, Omasa K, Horie T (2000) High temperature at flowering inhibits swelling of pollen grains, a driving force for thecae dehiscence in rice. Plant Prod Sci 3:430-434

Matsui T, Omasa K, Horie T (2001a) Comparison between anthers of two rice cultivars with tolerance to high temperature at flowering or susceptibility. Plant Prod Sci 4:36-40

Matsui T, Omasa K, Horie T (2001b) The differences in sterility due to high temperature during the flowering period among japonica rice varieties. Plant Prod Sci 4:90-93

Matsui T, Kobayasi K, Yoshimoto M, Hasegawa T (2007) Stability of rice pollination in the field under hot and dry conditions in the Riverina Region of New South Wales, Australia. Plant Prod Sci 10:57-63 
Matsushima S, Ikewada H, Maeda A, Honda S, Niki H (1982) Studies on rice cultivation in the tropics. I. Yielding and ripening responses of the rice plant to the extremely hot and dry climate in Sudan. Jpn J Trop Agric 26:19-25

Matthews RB, Kropff MJ, Bachelet D, Laar HV (1995) Modelling the impact of climate change on rice production in Asia. Springer, International Rice Research Institute, Berlin, Los Baños

Mohammed RA, Tarpley L (2011) Effects of night temperature, spikelet position and salicylic acid on yield and yield-related parameters of rice plants. J Agron Crop Sci 197:40-49

Morita S, Yonemaru J, Takanashi J (2005) Grain growth and endosperm cell size under high night temperatures in rice. Ann Bot 95:695-701

Morita S, Wada H, Matsue Y (2016) Countermeasures for heat damage in rice grain quality under climate change. Plant Prod Sci 19:1-11

Nishiyama I, Blanco L (1980) Avoidance of high temperature sterility by flower opening in the early morning. Jpn Agric Res Q 14:116-117

Nishiyama I, Satake T (1981) High temperature damage in the rice plant. Jpn J Trop Agric 25:14-19

NOAA (2011) State of the climate: global analysis for annual 2011. NOAA, Washington, DC. http://www.ncdc.noaa.gov/sotc/global/2011/13. Accessed 6 Aug 2018

Osada A, Sasiprapa V, Rahong M, Dhammanuvong S, Chakrabandho H (1973) Abnormal occurrence of empty grains of indica rice plants in the dry hot season in Thailand. Proc Crop Sci Soc Jpn 42:103-109

Pachauri RK, Reisinger A (2007) Climate change 2007: synthesis report. IPCC, Geneva

Peng S, Huang J, Sheehy JE, Laza RC, Visperas RM, Zhong X, Centeno GS, Khush GS, Cassman KG (2004) Rice yields decline with higher night temperature from global warming. Proc Natl Acad Sci U S A 101:9971-9975

Poli Y, Basava RK, Panigrahy M, Vinukonda VP, Dokula NR, Voleti SR, Desiraju S, Neelamraju S (2013) Characterization of a Nagina22 rice mutant for heat tolerance and mapping of yield traits. Rice 6:36

Prasad PVV, Boote KJ, Allen LH, Sheehy JE, Thomas J (2006) Species, ecotype and cultivar differences in spikelet fertility and harvest index of rice in response to high temperature stress. Field Crop Res 95:398-411

Raddatz G, Dehio M, Meyer TF, Dehio C (2001) PrimeArray: genome-scale primer design for DNA-microarray construction. Bioinformatics 17:98-99

Rosenzweig C, Iglesias A, Yang XB, Epstein PR, Chivian E (2001) Climate change and extreme weather events. Glob Change Hum Health 2:90-104

Satake T, Yoshida S (1978) High temperature induced sterility in Indica rice at flowering. Jpn J Crop Sci 47:6-17

Scafaro AP, Haynes PA, Atwell B (2010) Physiological and molecular changes in Oryza meridionalis Ng., a heat-tolerant species of wild rice. J Exp Bot 61:191-202

Shah F, Huang J, Cui K, Nie L, Shah T, Chen C, Wang K (2011) Impact of high-temperature stress on rice plant and its traits related to tolerance. J Agric Sci 149:545-556

Shanmugavadivel PS, Mithra SVA, Prakash C, Ramkumar MK, Tiwari R, Mohapatra T, Singh N (2017) High resolution mapping of QTLs for heat tolerance in rice using a 5K SNP array. Rice 10:28

Shi W, Ishimaru T, Gannaban RB, Oane W, Jagadish S (2015) Popular rice cultivars show contrasting responses to heat stress at gametogenesis and anthesis. Crop Sci 55:589-596

Solomon S, Qin D, Manning M, Chen Z, Marquis M, Averyt K, Tigno M, Miller H (2007) IPCC AR4 WG1. Climate change 2007: the physical science basis. Cambridge University Press, Cambridge

Tabaldi C, Hayhoe K, Arblaster J, Meehl G (2006) Going to the extremes. Climate Change 79:185-211

Takeoka Y, Mamun A, Wada T, Kaufman P (1992) Primary features of the effect of environmental stress on rice spikelet morphogenesis. Dev Crop Sci 22:113-141 
Tang RS, Zheng JC, Jin ZQ, Zhang DD, Huang YH, Chen L (2008) Possible correlation between high temperature-induced floret sterility and endogenous levels of IAA, GAs and ABA in rice. Plant Growth Regul 54:37-43

Tanveer T, Kobayashi Y, Koyama H, Matsui T (2015) QTL analyses for anther length and dehiscence at flowering as traits for the tolerance of extreme temperatures in rice. Euphytica 203:629-642

Tao L, Tan H, Wang X, Cao L, Song J, Chen S (2008) Effects of high-temperature stress on flowering and grain-setting characteristics of Guodao 6. Acta Agron Sin 34:609-614

Teixeira E, Fischer G, Velthuizen H, Walter C, Ewert F (2011) Global hot-spots of heat stress on agricultural crops due to climate change. Agric For Meteorol 170:206-215

Tenorio FA, Ye C, Redoña E, Sierra S, Laza M, Argayoso MA (2013) Screening rice genetic resources for heat tolerance. SABRAO J Breed Genet 45:341-351

Tian X, Luo H, Zhou H, Wu C (2009) Research on heat stress of rice in China: progress and prospect. Chin Agric Sci Bull 25:166-168

Tian X, Matsui T, Li S, Yoshimoto M, Kobayasi K, Hasegawa T (2010) Heat-induced floret sterility of hybrid rice (Oryza sativa L.) cultivars under humid and low wind conditions in the field of Jianghan basin, China. Plant Prod Sci 13:243-251

Varshney RK, Graner A, Sorrells M (2005) Genomics-assisted breeding for crop improvement. Trends Plant Sci 10:621-630

Vivitha P, Raveendran M, Vijayalakshmi D (2017) Introgression of QTLs controlling spikelet fertility maintains membrane integrity and grain yield in Improved White Ponni derived progenies exposed to heat stress. Rice Sci 24:32-40

Wahid A, Gelani S, Ashraf M, Foolad M (2007) Heat tolerance in plants: an overview. Environ Exp Bot 61:199-223

Wassmann R, Jagadish SVK, Heuer S, Ismail A, Redoña E, Serraj R, Singh RK, Howell G, Pathak $\mathrm{H}$, Sumfleth K (2009a) Climate change affecting rice production: the physiological and agronomic basis for possible adaptation strategies. Adv Agron 101:59-122

Wassmann R, Jagadish SVK, Sumfleth K, Pathak H, Howell G, Ismail A, Serraj R, Redoña E, Singh RK, Heuer S (2009b) Regional vulnerability of climate change impacts on Asian rice production and scope for adaptation. Adv Agron 102:91-133

Weerakoon W, Maruyama A, Ohba K (2008) Impact of humidity on temperature-induced grain sterility in rice. J Agron Crop Sci 194:135-140

Wei H, Liu J, Wang Y, Huang N, Zhang X, Wang L, Zhang J, Tu J, Zhong X (2013) A dominant major locus in chromosome 9 of rice (Oryza sativa L.) confers tolerance to $48^{\circ} \mathrm{C}$ high temperature at seedling stage. J Hered 104:287-294

Xia M, Qi H (2004) Effects of high temperature on the seed setting percent of hybrid rice breed with four male sterile lines. Hubei Agric Sci 2:21-22

Xiao Y, Pan Y, Luo L, Deng H, Zhang G, Tang W, Chen L (2011a) Quantitative trait loci associated with pollen fertility under high temperature stress at flowering stage in rice. Rice Sci 18:204-209

Xiao Y, Pan Y, Luo L, Zhang G, Deng H, Dai L, Liu X, Tang W, Chen L, Wang G (2011b) Quantitative trait loci associated with seed set under high temperature stress at the flowering stage in rice. Euphytica 178:331-338

Yamakawa H, Hirose T, Kuroda M, Yamaguchi T (2007) Comprehensive expression profiling of rice grain filling-related genes under high temperature using DNA microarray. Plant Physiol 144:258-277

Yan C, Ding Y, Wang Q, Liu Z, Li G, Muhammad I, Wang S (2010) The impact of relative humidity, genotypes and fertilizer application rates on panicle, leaf temperature, fertility and seed setting of rice. J Agric Sci 148:329-339

Yang C, Heilman J (1993) Responses of rice to short term high temperature: growth development and yield. J Agric Res China 42:1-11

Yang H, Huang ZQ, Jiang ZY, Wang X (2004) High temperature damage and its protective technologies of early and middle season rice in Anhui province. J Anhui Agric Sci 32:3-4 
Ye C, Argayoso M, Redoña E, Sierra S, Laza M, Dilla C, Mo Y, Thomson M, Chin J, Delaviña C, Diaz G, Hernandez J (2012) Mapping QTL for heat tolerance at flowering stage in rice using SNP markers. Plant Breed 131:33-41

Ye C, Tenorio F, Redoña E, Morales-Cortezano P, Cabrega G, Jagadish K, Gregorio G (2015a) Fine-mapping and validating $q H T S F 4.1$ to increase spikelet fertility under heat stress at flowering in rice. Theor Appl Genet 128:1507-1517

Ye C, Tenorio F, Argayoso M, Laza M, Koh H, Redoña E, Jagadish K, Gregorio G (2015b) Identifying and confirming quantitative trait loci associated with heat tolerance at flowering stage in different rice populations. BMC Genet 16:41

Yoshida S, Satake T, Mackill D (1981) High temperature stress in rice. IRRI Res Pap Ser 67:1-15

Zakaria S, Matsuda T, Tajima S, Nitta Y (2002) Effect of high temperature at ripening stage on the reserve accumulation in seed in some rice cultivars. Plant Prod Sci 5:160-168

Zhang T, Yang L, Jiang K, Huang M, Sun Q, Chen W, Zheng J (2008) QTL mapping for heat tolerance of the tassel period of rice. Mol Plant Breed 6:867-873

Zhang G, Chen L, Xiao G, Xiao Y, Chen X, Zhang S (2009) Bulked segregant analysis to detect QTL related to heat tolerance in rice using SSR markers. Agric Sci China 8:482-487

Zhao Z, Zhang L, Xiao Y, Zhang W, Zhai H, Wan J (2006) Identification of QTLs for heat tolerance at the booting stage in rice. Acta Agron Sin 32:640-644

Zhong L, Cheng F, Wen X, Sun X, Zhang G (2005) The deterioration of eating and cooking quality caused by high temperature during grain filling in early-season indica rice cultivars. J Agron Crop Sci 191:218-225

Zhou Y, Gong H, Li C, Hu C, Lin T, Sheng S (2009) Influence of thermal damage on seed-setting rate of 67 indica hybrid rice combinations. Acta Agric Jiangxi 21:23-26

Zhu C, Xiao Y, Wang C, Jiang L, Zhai H, Wan J (2005) Mapping QTLs for heat tolerance during grain filling in rice. Chin J Rice Sci 19:117-121

Ziska LH, Manalo PA, Ordonez R (1996) Intraspecific variation in the response of rice (Oryza sativa L.) to increased $\mathrm{CO}_{2}$ and temperature: growth and yield response of 17 cultivars. J Exp Bot 47:1353-1359

Open Access This chapter is licensed under the terms of the Creative Commons Attribution 4.0 International License (http://creativecommons.org/licenses/by/4.0/), which permits use, sharing, adaptation, distribution and reproduction in any medium or format, as long as you give appropriate credit to the original author(s) and the source, provide a link to the Creative Commons license and indicate if changes were made.

The images or other third party material in this chapter are included in the chapter's Creative Commons license, unless indicated otherwise in a credit line to the material. If material is not included in the chapter's Creative Commons license and your intended use is not permitted by statutory regulation or exceeds the permitted use, you will need to obtain permission directly from the copyright holder.

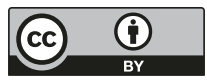

